\title{
IT ISN'T CRAZY: WHY INDIANA SHOULD RE-EVALUATE ItS MENTAL HEALTH RELATED BAR EXAM APPLICATION QUESTIONS
}

\author{
Bailey L. Box*
}

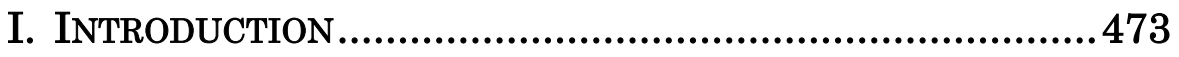

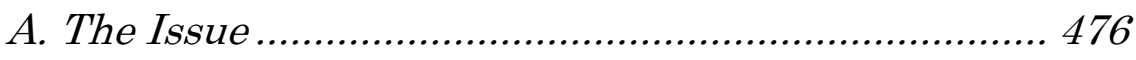

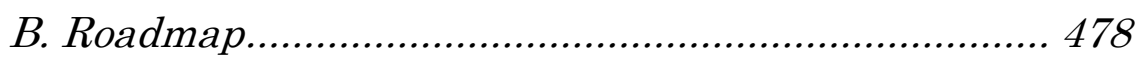

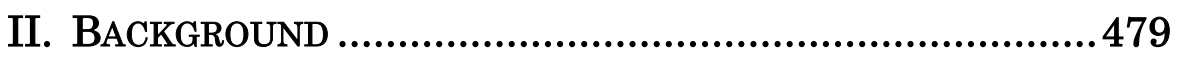

A. Bar Exam Applications: Character and

Fitness Requirement ............................................. 479

B. The Americans with Disabilities Act ...................... 482

C. Public Policy .......................................................... 485

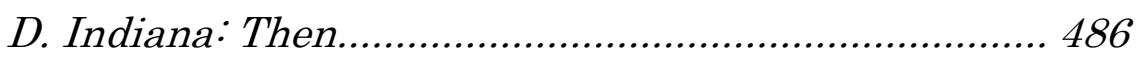

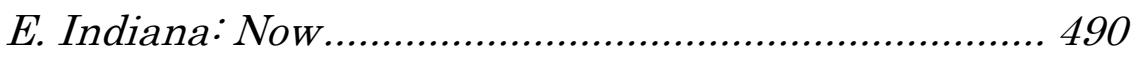

F. Department of Justice's Stance on Mental

Health Inquiries ................................................... 492

G. The National Conference of Bar

Examiners' Response............................................... 497

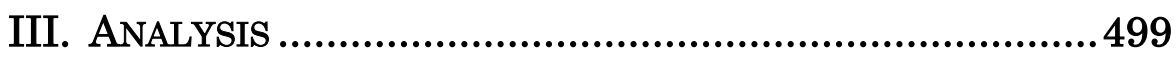

A. A Look at Indiana's Current Questions ................. 499

1. Question 25 .................................................... 499

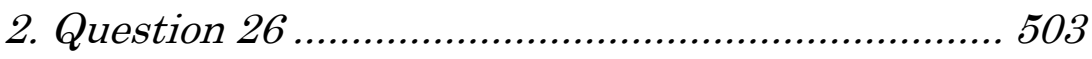

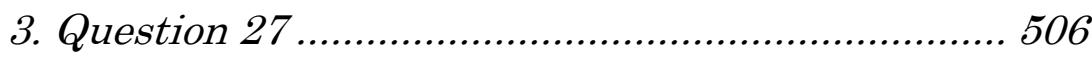

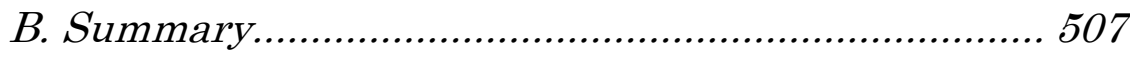

IV. CONCLUSION ….....................................................507

* J.D. Candidate, 2016, Indiana University Robert H. McKinney School of Law; M.B.A. Candidate, 2016, Indiana University Kelley School of Business; B.A., 2012, Miami University. For her exemplary work on this Note, Bailey L. Box received the Indiana Health Law Review's Best Note Award for Volume XII. 


\section{INTRODUCTION}

Any aspiring law student that has asked practicing attorneys what he or she could expect from the practice of law has likely been met with many of the same answers: high stress, long hours, demanding work environments, and tedious work projects. However, despite being aware of some of the less than ideal demands of the legal profession, students continue to go to law school. Although law schools have seen a decline in admissions since the recession, as of April 2016, 51,000 students had applied to American law schools for fall 2016 admission. ${ }^{1}$

While the stressful and tedious aspects of the legal profession certainly do not apply to every attorney at every firm or in every organization, these generalizations are widespread enough, and perhaps for good reason. Attorneys "are 3.6 times more likely to suffer from depression than" non-attorneys. ${ }^{2}$ However, this problem does not just affect practicing attorneys, nor are the terms "high stress," "demanding," and "tedious" ones that apply solely to the practice of law - they are prevalent in the law school culture as well.

The first year of law school is often a shock to students, because for many it is their first experience with the Socratic method of teaching. Rather than merely attending a lecture, students are expected to be prepared to be called upon to answer any number of questions about an assigned case or a tangential hypothetical. ${ }^{3}$ While some professors are much more demanding than others, the adjustment to this method

\footnotetext{
${ }^{1}$ Elizabeth Olson, Minnesota Law School, Facing Waning Interest, Cuts Admissions, N. Y. Times (May 12, 2016), available at http://www.nytimes.com/2016/05/13/business/dealbook/minnesota-lawschool-facing-waning-interest-cuts-admissions.html [https://perma.cc/ 6E3R-MA2P].

2 Rosa Flores \& Rose Marie Arce, Why are Lawyers Killing Themselves?, CNN U.S. (Jan. 20, 2014, 2:42 PM), http:// www.cnn.com/2014/01/19/us/lawyer-suicides/ [https://perma.cc/82F8ZX4Q].

3 See generally Robert J. Rhee, The Socratic Method and the Mathematical Heuristic of George Pólya, 81 ST. JoHN’s L. REV. 881 (2007) (discussing the Socratic method).
} 
of teaching is one that is often met with sweaty palms and a nervous stomach. ${ }^{4}$ Further, the realization that each fellow classmate is your competition - thanks to grading on a strict bell curve - can lead to tense academic environments, and in extreme situations, an unwillingness of students to help one another with coursework. Add to this adjustment the pressure of meeting expectations, staying on top of reading assignments, and landing internships that will ideally lead to gainful employment after graduation, it is unsurprising that by the time law students reach the end of their third which for many is their final - year of law school, $40 \%$ of them suffer from signs and symptoms of depression. ${ }^{5}$ These rates may be even higher at certain institutions, as a recent study conducted at Yale Law School revealed that 70\% of students surveyed reported experiencing mental health challenges during law school. ${ }^{6}$

Unfortunately, students that feel depressed, anxiety ridden, or overly stressed by the pressures of law school may be inclined to think twice before seeking professional treatment for these symptoms. ${ }^{7}$ In order to be admitted to the bar in any state, graduated law students must not only

4 Christopher J. Yianilos, The LaW School Breakthrough: Graduate In The ToP 10\% OF Your Class, Even IF You'Re Not a FirstRATE STUDENT 38 (Gina M. Cheselka, ed., 2005).

${ }^{5}$ G. Andrew H. Benjamin, Reclaim Your Practice, Reclaim Your Life, TRIAL, Dec. 2008, at 30, available at http:// www.lawyerswithdepression.com/wp-content/uploads/2015/02/ Trail.HowStressandAnxietyBeccomeDepression.December.2008-1.pdf [https://perma.cc/M6UP-Z9FZ]; see also G. Andrew H. Benjamin et al., The Role of Legal Education in Producing Psychological Distress Amount Law Students and Lawyers, 1986 AM. B. Found. RES. J. 225; Stephen B. Shanfield \& G. Andrew H. Benjamin, Psychiatric Distress in Law Students, 35 J. LEGAL EDUC. 65 (1985); Kate Mayer Mangan, Law School Quadruples the Chances of Depression for Tens of Thousands: Some Changes That Might Help, HufFInGton Post (Aug. 8, 2014) www.huffingtonpost.com/kate-mayer-mangan/law-school-quadruplesdep_b_5713337.html [https://perma.cc/S5WE-4AGA].

${ }^{6}$ Yale LaW School Mental Health Alliance, Falling Through The CRacks: A Report on Mental Health at Yale LaW School 3 (2014), available at www.scribd.com/doc/252727812/Falling-Throughthe-Cracks\#scribd [https://perma.cc/8DHC-6AFK].

${ }^{7}$ Laura Rothstein, Law Students and Lawyers with Mental Health and Substance Abuse Problems: Protecting the Public and the Individual, 69 U. PITT L. REV. 531, 533 (2008). 
pass the state's bar exam, 8 but in order to sit for the examination, the student must also pass the state's character and fitness application. 9 The National Conference of Bar Examiners ("NCBE") provides a set of model character and fitness questions that many states use on their bar applications verbatim. ${ }^{10}$

Taking into account the heightened rate of attorneys who experience depression and the often high-stress nature of both law school and the practice of law, it is not surprising that a majority of states inquire into bar exam applicants' mental health histories. However, for the applicants that are required to disclose information regarding their mental health histories to the state's board of examiners, the outcomes that those applicants may face range greatly. In some instances, no additional actions are taken. ${ }^{11}$ However, there is the possibility that the state bar will request additional information, such as medical records, from the applicant; that it will only allow the applicant to be admitted to the bar on a conditional basis; or the most extreme outcome: a complete denial of admission to the state's bar. ${ }^{12}$

8 There is one exception to the requirement that an individual must have successfully passed the bar exam in order to practice law within the state. In Wisconsin, students that graduate from the University of Wisconsin Law School and Marquette University Law School are admitted to the practice of law by having the school certify their legal compliance and having the Board of Examiners certify their character and fitness. Elizabeth Olson, Bar Exam, the Standard to Become a Lawyer Comes Under Fire, N. Y. Times (Mar. 19, 2015), available at http://www.nytimes.com/2015/03/20/business/dealbook/bar-exam-thestandard-to-become-a-lawyer-comes-under-fire.html?_r=0 [https://perma.cc/65KA-S4D9].

${ }^{9}$ Clark v. Va. Bd. of Bar Exam'rs, 880 F. Supp. 430, 438 (E.D. Va. 1995).

10 NAT'L CONF.of BAR EXAM'Rs, REQUEST FOR PREPARATION OF A CHARACTER REPORT 13-14, available at www.ncbex.org/dmsdocument/134 [https://perma.cc/4KB3-YEBZ].

11 Melody Moezzi, Lawyers of Sound Mind?, N.Y. Times (Aug. 5, 2013), available at http://www.nytimes.com/2013/08/06/opinion/lawyersof-sound-mind.html?_r=0. [https://perma.cc/5LV4-5CME].

${ }_{12} I d$. 


\section{A. The Issue}

Because of the sensitive nature of questions regarding applicants' mental health histories, the way in which these inquiries take place has been, and continues to be, a subject of great debate. Many bar exam applicants and legal scholars believe that inquiring into bar exam applicants' mental health histories is not only an unnecessary invasion of an applicant's privacy, but also a violation of the Americans with Disabilities Act ("ADA"). ${ }^{13}$

In 2011, the Southern District of Indiana found in the case of $A C L U$ of Indiana v. Individual Members of the Indiana State Board of Law Examiners that out of the four Indiana bar exam application questions regarding applicants' mental health, only one question - which asked bar applicants to disclose any mental, emotional, or nervous disorders they may have had from age sixteen to present - was a violation of the ADA. ${ }^{14}$ However, the three remaining questions, which also took a broad look into applicants' mental health histories, were allowed to stand. ${ }^{15}$ While the court took a step in the right direction by eliminating one question that looked too expansively into applicants' mental health histories, it was not a big enough step to ensure Indiana's compliance with Title II of the ADA, and to ensure that such inquiries meet the intended goals.

In 2016, the Indiana Board of Law Examiners asked the following questions of Indiana bar exam applicants:

25. Within the past five (5) years have you been diagnosed with or have you been treated for bi-

${ }^{13}$ See, e.g., Marian Alikhan, The ADA is Narrowing Mental Health Inquiries on Bar Applications: Looking to the Medical Profession to Decide Where to Go From Here, 14 GEO. J. LeGAL ETHICs 159 (2000); Alex B. Long, Reasonable Accommodations as Professional Responsibility, Reasonable Accommodation as Professionalism, 47 U.C. DAVIS L. REV. 1753 (2014); Jon Bauer, The Character of the Questions and the Fitness of the Process: Mental Health, Bar Admissions, and the Americans With Disabilities Act, 49 UCLA L. REV. 93 (2001).

14 ACLU of Ind. v. Individual Members of the Ind. State Bd. Of Law Exam'rs, No. 1:09-CV-824-TWP-MJD, 2011 WL 4387470, at *13 (S.D. Ind. Sept. 20, 2011).

${ }^{15} I d$. 
polar disorder, depression, or other emotional disorder, schizophrenia, paranoia, or any other psychotic disorder? ${ }^{16}$

26A. Do you have any condition or impairment (including but not limited to, substance abuse, alcohol abuse, or a mental, emotional, or nervous disorder or condition) which in any way currently affects, or if untreated could affect, your ability to practice law in a competent manner? ${ }^{17}$

26B. Are the limitations or impairments caused by your mental health condition or substance abuse problem reduced or ameliorated because you receive ongoing treatment (with or without medication) or because you participate in a monitoring program? ${ }^{18}$

27. Have you ever raised the issue of consumption of drugs or alcohol or the issue of a mental, emotional, nervous, or behavioral disorder or condition as a defense, mitigation, or an explanation for your actions in the course of any administrative or judicial proceeding or investigation, any inquiry or other proceeding, or any proposed termination by any educational institution, employer, government agency, professional organization or licensing authority? ${ }^{19}$

As they stand, not all of the Indiana state bar exam application questions pertaining to applicants' mental health focus on the applicants' behavior or conduct that could impact their ability to practice law. Instead, the questions posed to bar exam applicants focus solely on their mental health conditions. The expansive scope of these questions may also

${ }^{16}$ Ind. Supreme Court Bd. of Law Exam'rs, Character \& Fitness Questionnaire, APPLICATION INFORMATION (2016), available at https://myble.courts.in.gov/browseapplication.action?id=9 (select "Browse Form" beside "Character and Fitness Questionnaire," then click "General Questions" in the dropdown bar) (last visited Apr. 20, 2016).

$17 I d$.

$18 I d$. (To see the text of this question, respond "Yes" to question 26A).

${ }^{19} I d$. 
serve as a deterrent for individuals with symptoms of mental illness to seek help during their law school years, or as a deterrent for those who have been diagnosed with mental illness from truthfully disclosing information related to their mental health histories. The negative ramifications of not having properly tailored questions regarding applicants' mental health histories not only have the potential to impact the applicants themselves, but also the applicants' coworkers, clients, and the Indiana legal community as a whole.

\section{B. Roadmap}

Although the questions posed to Indiana bar exam applicants regarding their mental health histories are far less intrusive than they were prior to the court's holding in $A C L U$ of Indiana, as they are currently written, the questions are still too broad and risk infringing upon the privacy afforded to each applicant under Title II of the ADA. This Note will address the importance of the Indiana Board of Law Examiners re-evaluating the way in which Indiana looks into bar exam applicants' mental health histories, and shifting its inquiry to one that is more focused on the conduct of the applicants rather than solely on their conditions.

First, this Note will provide background on the character and fitness requirements that bar exam applicants must meet, Title II of the ADA, and why many character and fitness questions related to mental health are challenged as a violation of Title II of the ADA. The evolution of Indiana's character and fitness questions related to mental health will be reviewed, and a February 5, 2014 letter from the United States Department of Justice ("DOJ") in regard to its stance on states' inquiries into applicants' mental health histories will be discussed. Next, current questions that the Indiana Board of Law Examiners is posing to its applicants will be analyzed to determine how well applicants are being protected under the rights afforded to them by Title II of the ADA. Finally, this Note will focus on the ways in which the Indiana Bar and its applicants may benefit from a reevaluation of the current character and fitness questions related to mental health. 


\section{BACKGROUND}

\section{A. Bar Exam Applications: Character and Fitness Requirement}

While the academic requirements a bar exam applicant must meet to become licensed in any given state in America have evolved over the years, the prerequisite that an applicant be one of virtue has been a constant. ${ }^{20}$ However in today's society, boards of law examiners are looking for far more than virtue alone in the applicants hoping to become licensed attorneys. Rather, these licensing boards are looking for a thorough assessment of an individual's character and fitness. ${ }^{21}$

The importance in ensuring that an attorney meets requisite character and fitness standards lies in both "protecting the public" and in "preserving professionalism." 22 If an attorney is affected by an untreated mental or emotional illness, he or she may pose a possible risk to clients, colleagues, and the public, because some mental illnesses, if not properly treated, can negatively impact an individual's ability to competently and skillfully practice law. ${ }^{23}$ State bar authorities require applicants to meet certain character and fitness criteria in order to sit for the state's bar examination. ${ }^{24}$ However, states' definitions of "fitness" are not unanimous, and the criteria upon which they use to

${ }^{20}$ Deborah L. Rhode, Moral Character as a Professional Credential, 94 YALE L.J. 491, 496 (1985).

${ }^{21}$ Aaron M. Clemens, Facing the Klieg Lights: Understanding the "Good Moral Character" Examination for Bar Applicants, 40 AKRON L. REV. 255, 257 (2007) (discussing that state bar examiners often look into several aspects of an applicant's past to determine whether the applicant has good moral character, such as his or her "financial [responsibility], past criminal history, mental illness and treatment, substance abuse, lack of academic integrity, and failure to cooperate with bar examiners. . ..”).

${ }^{22}$ Rhode, supra note 20, at 507-512.

23 Jennifer McPherson Hughes, Suffering in Silence: Questions Regarding an Applicant's Mental Health on Bar Applications and Their Effect on Law Students Needing Treatment, 28 J. LEGAL PROF. 187, 188 (2004).

${ }^{24}$ Marcus Ratcliff, The Good Character Requirement: A Proposal for a Uniform National Standard, 36 TULSA L.J. 487, 492 (2000). 
evaluate applicants to determine whether they meet the established definition vary widely on a state-by-state basis. ${ }^{25}$ Although the criteria and questions posed to applicants may vary, the methods in which these questions are posed are relatively similar. In most states, the character investigation takes place through a questionnaire completed by each applicant; however, some states have an added step requiring each candidate to undergo an in-person interview. ${ }^{26}$

For an individual to be admitted to practice law in Indiana, the applicant has the "burden of proving that he or she possesses the requisite good moral character and fitness to practice law." 27 In Indiana, "[t]he term 'good moral character' includes, but is not limited to, the qualities of honesty, fairness, candor, trustworthiness, observance of fiduciary responsibility, and of the laws of this State and of the United States, and a respect for the rights of other persons and things, and the judicial process." 28 The term "fitness" relates to the "physical and mental suitability of the applicant to practice law...."29 In addition to completing the Character and Fitness Questionnaire, every Indiana bar exam applicant must undergo an in-person character interview by a member of the committee or a member designated by the Board of Law Examiners. ${ }^{30}$

In Clark v. Virginia Board of Bar Examiners, an action brought by a 1993 graduate of George Mason University Law School against the Virginia Board of Bar Examiners, the United States District Court in the Eastern District of Virginia examined how states asked bar exam applicants about their mental health histories. ${ }^{31}$ The court explained that states handled mental health inquiries in the following ways: (1) not looking into applicants' mental health histories, (2) asking only about hospitalization or institutionalization

\footnotetext{
${ }^{25} I d$.

${ }^{26} I d$.

27 IN. ST. AdMis. AND Disc. R. $12 \S 2$ (2014).

${ }^{28} I d$.

${ }^{29} \mathrm{Id}$.

${ }^{30} I d . \S 4$.

${ }^{31}$ Clark v. Va Bd. of Bar Exam'rs, 880 F.Supp. 430, 438-440 (E.D. Va.
} 1995). 
for mental illness, and (3) inquiring broadly into applicants' treatment and/or counseling for mental and emotional disorders or illnesses. ${ }^{32}$

Due to the vast differences in how states question applicants about their mental health histories, passing muster for one state's character and fitness examination does not mean that an applicant will subsequently be able to meet the standards of another state, even if he or she has been proven competent to practice. In one instance, a Harvard Law School graduate, who had been diagnosed with bipolar disorder as a law student, was admitted to practice in both New York and Massachusetts. ${ }^{33}$ However, when she applied to the Connecticut bar in the mid-1990s, she disclosed her mental illness and was not recommended for admission. ${ }^{34}$ It took a lengthy judicial process for her to gain conditional admission to the Connecticut bar. ${ }^{35}$ In order to maintain her conditional admission status, she was required to provide the Connecticut Bar Examining Committee with a "doctor's report and affidavit" twice a year to affirm that she was fit for the practice of law in Connecticut. ${ }^{36}$ The conditional admission status placed on this applicant, who had been previously admitted to bars in two different states, lasted for nine years. ${ }^{37}$

The individual that endured nine years of being only conditionally admitted to practice in the state of Connecticut is Kathleen Flaherty. ${ }^{38}$ After the tragic shooting that took place at Sandy Hook Elementary School in Newton, Connecticut in $2013,{ }^{39} \mathrm{Ms}$. Flaherty was appointed to the

\footnotetext{
${ }^{32} I d$.

33 Moezzi, supra note 11; Debra Cassens Weiss, Lawyer Says Her Experience With Bipolar Disorder is Reason for Appointment to Sandy Hook Commission, ABA J. (Jan. 15, 2013, 6:11 PM), http:// www.abajournal.com/news/article/lawyer_says_her_experience_with_bip olar_disorder_is_reason_for_appointment_/ [http://perma.cc/SBL9UR85].

34 Moezzi, supra note 11.

${ }^{35} I d$.

${ }^{36} I d$.

${ }_{37} I d$.

${ }^{38} I d$.

${ }^{39}$ On December 14, 2012, 20-year old Adam Lanza entered Sandy Hook Elementary School and killed 20 children and six adult school
} 
Sandy Hook Advisory Commission by Connecticut's Governor, Dannel P. Malloy. ${ }^{40}$ Ms. Flaherty credits her personal experience with bipolar disorder as to why she was personally asked to serve on the commission. ${ }^{41}$

Instances such as these raise the question as to whether there is a correct way to ask applicants about their mental health histories, or if they should be inquired into at all. Had Ms. Flaherty been deterred from seeking admission to Connecticut's bar based upon her history of mental health related issues, or had she been unwilling to meet the extra requirements placed upon her to maintain her conditional admittance status that lasted for almost a decade, the state of Connecticut likely would not have benefitted from her knowledge, experience, and expertise in the wake of an unspeakable tragedy that stemmed from one individual's struggle with mental illness. ${ }^{42}$ The line between adequately screening for individuals that may be a harm to themselves or to others based upon their mental health histories and violating the rights afforded to applicants under Title II of the ADA is a fine one. Thus, it is of the utmost importance for Indiana to take an objective look at the impact that the mental health inquiries on the character and fitness portion of its application are having on the individuals seeking admittance to the Indiana bar.

\section{B. The Americans with Disabilities Act}

The ADA, enacted in 1990, was created "to provide a clear and comprehensive national mandate for the elimination of

employees. See James Barron, Nation Reels After Gunman Massacres 20 Children at School in Connecticut, N.Y. TIMES (Dec. 14, 2012) http://www.nytimes.com/2012/12/15/nyregion/shooting-reported-atconnecticut-elementary-school.html [perma.cc/E5R4-H288].

${ }^{40} I d$.

${ }^{41}$ Weiss, supra note 33.

42 Alison Leigh Cowan, Adam Lanza's Mental Problems 'Completely Untreated' Before Newton Shootings, Report Says, N.Y. Times (Nov. 21, 2014), http://www.nytimes.com/2014/11/22/nyregion/before-newtownshootings-adam-lanzas-mental-problems-completely-untreated-reportsays.html [perma.cc/3M7V-Y6HU] (discussing that Adam Lanza went untreated for "psychiatric and physical ailments like anxiety and obsessive-compulsive disorder"). 
discrimination against individuals with disabilities." 43 Prior to its enactment, individuals that were discriminated against based upon their disabilities were not afforded the same federal protection against discrimination that individuals who experienced discrimination based upon their "race, sex, religion, national origin, and age had." 44 Since the ADA went into effect over twenty-five years ago, numerous federal and state court decisions have discussed the interplay between the ADA and state bar examiners' inquiries into applicants' mental health histories. ${ }^{45}$

The ADA serves to protect individuals with disabilities. The Act defines "disability," with respect to an individual, as (1) "a physical or mental impairment that substantially limits one or more major life activities of such individual;" (2) "a record of such an impairment;" or (3) "being regarded as having such an impairment." 46 Title II of the ADA was enacted to prohibit discrimination against individuals by public entities, as it states that "no qualified individual with a disability shall, by reason of such disability, be excluded from participation in or be denied the benefits of the services, programs, or activities of a public entity, or be subjected to discrimination by any such entity." 47 "Public entity" is defined as "any State or local government" or "any department, agency, special purpose district, or other instrumentality of a State or States or local government. . . .$" 48$

Regulations, such as those discussed below, were put into place to "indicate that coverage extends to the activities of the state judicial branch and to state licensing programs." 49 State bar examiners are widely considered to act as an arm of the state judiciary, and thus are covered by the

4342 U.S.C. $\S 12101(b)(1)$ (2016).

${ }^{44}$ Cary LaCheen, Using Title II of the Americans With Disabilities Act On Behalf of Clients in TANF Programs, 8 GEO. J. ON POVERTY L. \& POL'Y 1, 37 (2001).

45 Bauer, supra note 13 , at $125-126$.

4642 U.S.C. $§ 12102(1)$ (2016).

47 Id. $§ 12132$.

${ }^{48}$ Id. $\S 12131(1)$.

${ }^{49}$ Bauer, supra note 13, at 128. 
requirements in Title II. ${ }^{50}$ More specifically, the ADA has been held to apply to questions asked to applicants by legal licensing boards. ${ }^{51}$

The ADA clearly states that a public entity may not "directly or through contractual or other arrangements, utilize criteria or methods of administration ... [t] hat have the effect of subjecting qualified individuals with disabilities to discrimination on the basis of disability." 52 In specific reference to licensing, "[a] public entity may not administer a licensing or certification program in a manner that subjects qualified individuals with disabilities to discrimination on the basis of a disability." 53

Further, in the course of administering such licensing or certification programs, "a public entity shall not impose or apply eligibility criteria that screen out or tend to screen out an individual with a disability or any class of individuals with disabilities from fully and equally enjoying any service, program, or activity, unless such criteria can be shown to be necessary." 54

Although a public entity is allowed to put in place certain safety requirements to ensure "safe operation of its services, programs, or activities," such requirements must be "based

${ }^{50}$ Id.; See also ACLU of Ind. v. Individual Members of the Ind. State Bd. Of Law Exam'rs, No. 1:09-CV-824-TWP-MJD, 2011 WL 4387470, at *5 (S.D. Ind. Sept. 20, 2011); Ware v. Wyo. Bd. of Law Exam'rs, 973 F.Supp 1339, 1352 (D. Wyo. 1997); Ellen S. v. Fla. Bd. of Bar Exam'rs, 859 F. Supp. 1489, 1493 n. 4 (S.D. Fla. 1994).

${ }^{51}$ See, e.g., Clark v. Va. Bd. of Law Exam'rs, 880 F. Supp. 430, 446 (E.D. Va. 1995) (holding that a question inquiring into applicants' mental health was too broadly worded and discriminated against disabled applicants); Ellen S., 859 F. Supp. at 1493-94 (holding that Florida's bar exam application questions pertaining to mental health discriminate against Plaintiffs by placing additional burdens on them because of their disability); Application of Underwood, No. BAR-93-21, 1993 WL 649283, at *112 (Me. Dec. 7, 1993) (holding that requirement that Maine bar applicants answer mental health questions "discriminates on the basis of disability and imposes eligibility criteria that unnecessarily screen out individuals with disabilities.").

5228 C.F.R. § 35.130(b)(3)-(b)(3)(i) (2016).

${ }^{53} I d . \S 35.130(\mathrm{~b})(6)$.

${ }_{54}$ Id. $\S 35.130(\mathrm{~b})(8)$. 
on actual risks, not on mere speculation, stereotypes, or generalizations about individuals with disabilities." 55

If bar exam applicants feel that they have been discriminated against in violation of the ADA, there are several remedies available to them. First, the applicant may file an administrative complaint within 180 days of the discrimination occurring. ${ }^{56}$ Such complaint may be filed with an agency enumerated within the Title II regulations or with the Department of Justice. ${ }^{57}$ Alternatively, an applicant may file a lawsuit. ${ }^{58}$ Thus, if states' board of law examiners do not take it upon themselves to ensure that the methods being used to inquire into applicants' mental health histories are compliant with Title II of the ADA, it will be left for a court of law to determine, such as it was in ACLU of Indiana, and in several other jurisdictions throughout the country. ${ }^{59}$

\section{Public Policy}

Because of the number of law students and attorneys that experience depressive symptoms and mental health related issues, the public policy reasons behind many states inquiring into applicants' mental health histories are well taken. Safeguards need to be put in place that will ensure Indiana bar applicants are mentally fit to practice law, both for their own safety and wellbeing, and for the protection of those that they represent and interact with in a professional capacity.

However, the way in which the Indiana Board of Law Examiners chooses to screen applicants is crucial, both to reduce the number of false positives - applicants that are incorrectly flagged as being potentially unfit to practice law - during an application cycle and to protect the rights afforded to each applicant through Title II of the ADA. This

${ }^{55}$ Id. $\S 35.130(\mathrm{~h})$.

${ }^{56}$ Id. $\S 35.170(\mathrm{~b})$.

${ }^{57} I d . \S 35.170(\mathrm{c})$.

${ }^{58} I d . \S 35.172(\mathrm{~d})$.

59 See, e.g., Clark v. Va. Bd. of Law Exam'rs, 880 F. Supp. 430, 446 (E.D. Va. 1995); Ellen S. v. Fla. Bd. of Bar Exam'rs, 859 F. Supp. 1489, 1493 n. 4 (S.D. Fla. 1994); Application of Underwood, No. BAR-93-21, 1993 WL 649283, at *1 (Me. Dec. 7, 1993). 
will not only be beneficial for the applicants, but will also preserve the Board of Law Examiners' time and resources during the application cycle. If there is a more effective set of questions in place, the time and resources spent evaluating applicants that have been falsely identified as being unfit for the practice of law will be greatly reduced.

Additionally, apart from the benefits that the Indiana Board of Law Examiners will experience from Indiana revisiting its mental health related inquiries, there are also benefits for the applicants themselves. The broad nature of Indiana's current questions may deter individuals from attending law school out of fear of having to disclose their mental health status. It may deter law students who are experiencing mental health related symptoms from seeking treatment. Moreover, Indiana's current questions may cause students who have been diagnosed with or are being treated for mental illness from being truthful in their disclosures on the bar exam application.

\section{Indiana: Then}

In 2009, plaintiffs - students at what is now Robert $\mathrm{H}$. McKinney School of Law in Indianapolis Indiana, and a 2007 Valparaiso University School of Law graduate - filed a complaint against the Indiana Board of Law Examiners over four bar exam questions that they believed were too broad. 60

Amanda Perdue, the original sole Plaintiff to this case, was an Illinois attorney who hoped to sit for the bar exam in Indiana. ${ }^{61}$ Perdue had been diagnosed with anxiety disorder and posttraumatic stress disorder and she had undergone professional treatment for these conditions. ${ }^{62}$ Upon applying to sit for the Indiana bar exam in 2008, Perdue, like all applicants, completed the character and fitness portion of the application. ${ }^{63}$ Because of her mental health history, Perdue

${ }^{60}$ ACLU of Ind. v. Individual Members of the Ind. State Bd. Of Law Exam'rs, No. 1:09-CV-824-TWP-MJD, 2011 WL 4387470 (S.D. Ind. Sept. 20,2011 ).

61 Perdue v. Individual Members of Ind. State Bd. of Law Exam'rs, 266 F.R.D. 215, 217 (S.D. Ind. 2010).

${ }^{62} I d$.

${ }^{63} I d$. 
responded "yes" to question 23, which inquired into whether she had been diagnosed or treated for any type of emotional, mental, or nervous disorder from the age of 16 to present. ${ }^{64}$

Perdue's affirmative response triggered the Indiana Board of Law Examiners to request additional information regarding her mental health conditions and to refer Perdue to the Judges and Lawyers Assistance Program ("JLAP").65 JLAP is a program that was created in 1997 to provide help to judges, attorneys, and law students who experience physical or mental disabilities that result from disease, chemical dependency, mental health problems, or age, which may impair these individuals' ability to practice in a competent and professional manner. ${ }^{66}$

JLAP provides assistance to Indiana attorneys and law students in several ways, including providing them with information and connecting them to resources that can help organize an intervention. ${ }^{67}$

The Indiana Board of Law Examiners has the ability to refer any applicant to JLAP if it is concerned about the applicant's mental fitness. 68 In determining whether it will refer an applicant to the program, many factors are taken into consideration, including: "how recent the mental health issue was; whether it's episodic; whether it required continuing treatment; whether it resulted in hospitalization or arrest; and whether it resulted in loss of employment or licensing." 69

However, while the Indiana Board of Law Examiners has the ability to refer any individual to JLAP that it deems in need of JLAP's services, the individuals are not required to oblige. Perdue declined to consent to the requests and referral to JLAP. ${ }^{70}$ Instead, she subsequently withdrew her application and filed suit against the Indiana Board of Law

${ }^{64}$ ACLU of Ind., 2011 WL 4387470 at *4.

65 Perdue, 266 F.R.D. at 217.

${ }^{66}$ About JLAP, COURTS.IN.GOV, https://secure.in.gov/judiciary/ijlap/ 2361.htm [perma.cc/UD77-JTKB] (last visited Apr. 20, 2016).

$67 \mathrm{Id}$.

68 ACLU of Ind., 2011 WL 4387470, at *3.

${ }^{69} \mathrm{Id}$.

70 Perdue, 266 F.R.D. at 217. 
Examiners. ${ }^{71}$ The lawsuit, which was initially brought by Perdue, eventually became a class action with the American Civil Liberties Union ("ACLU") being appointed as the class representative. ${ }^{72}$

At the time Perdue filed her original complaint against the Indiana Board of Law Examiners, applicants applying for admission to the Indiana bar were asked the following four questions regarding their mental health histories:

22. Have you been diagnosed with or have you ever been treated for bi-polar disorder, schizophrenia, paranoia or any other psychotic disorder?

23. From the age of 16 years to the present, have you been diagnosed or treated for any mental, emotional, or nervous disorders?

24. Do you have any condition or impairment (including, but not limited to, substance abuse, alcohol abuse, or a mental, emotional, or nervous disorder or condition) which in any way currently affects, or if left untreated could affect, your ability to practice law in a competent and professional manner?

25. IF YOUR ANSWER TO QUESTION 24 IS AFFIRMATIVE, are the limitations or impairments caused by your mental health condition or substance abuse problem reduced or ameliorated because you receive ongoing treatment (with or without medication) or because you participate in a monitoring program $?^{73}$

If an applicant answered affirmatively to questions $22-25$, he or she was required to complete a B-1 form, which sought more information about the applicant's condition, diagnosis,

\footnotetext{
${ }^{71} I d$.

${ }^{72} I d$.

${ }^{73}$ ACLU of Ind., 2011 WL 4387470, at *2.
} 
treatment, and providers. ${ }^{74}$ These applicants were also required to sign a general release of information. ${ }^{75}$

The court summarized its duty in this case as "[resolving] whether the challenged questions are 'necessary' to determine whether the bar applicant poses a 'direct threat"' to the health and safety of themselves and of others. ${ }^{76}$ Ultimately, the court held that only one of these questions was in violation of the ADA - question 23 - which the court called "possibly the most expansive bar application question in the country." 77 It was reasoned to be too broad, to lead to too many false positives, and to have chosen an arbitrary time frame that was not a good indicator of an individual's current mental fitness to practice law. 78

The other three questions - question 22, which asked about applicants' histories of bi-polar disorder, schizophrenia, paranoia, or other psychotic disorders, and questions 24 and 25, which asked applicants about any condition or impairment that "currently affects," or if "left untreated could affect," his or her ability to practice law competently and professionally - however, were allowed to stand. ${ }^{79}$ Question 22, although it had no temporal limitation, was reasoned to involve "serious" mental illnesses that could be recurring in nature. ${ }^{80}$ Because of the likelihood that these enumerated conditions could reappear during an applicant's lifetime, its broad nature was not found to violate the ADA. 81 Questions 24 and 25 were not considered to violate the ADA because the court considered them "narrowly focused on the current time period" and focused on "the applicant's current ability to practice law." 82

However, in its opinion, the court looked at each question and considered its compliance with the ADA in depth. Ultimately, although it only struck down one question as

\footnotetext{
${ }^{74} I d$. at *3.

$75 \mathrm{Id}$.

76 Id.at *8.

${ }_{77} I d$. at $* 9$.

$78 I d$. at *9.

79 Id. at $* 8-13$.

${ }^{80} I d$. at * 7 .

81 Id. at *9.

82 Id. at * 10 .
} 
being too broad to comply with the ADA and allowed the remaining three questions to stand, the court did note that possibly no set of bar exam questions could perfectly meet both the need to screen problematic bar applicants and to "[respect] applicants' privacy." 83 The court is likely correct in its stance that there may never be a perfectly tailored set of questions that precisely meets each need that the character and fitness portion of states' bar exam applications are intended to serve. Even the most compliant set of questions will not perfectly screen all applicants, nor will all applicants necessarily respond truthfully to each question. Even so, this should not serve as a rationale for states to rest on their laurels and not re-evaluate the mental health related questions posed to bar exam applicants on a consistent basis. Thus, although the court struck one extremely broad question, Indiana should continually evaluate the questions it asks its bar exam applicants, as such re-evaluation is beneficial for the state, applicants themselves, and the clients and colleagues the applicants will work with.

\section{E. Indiana: Now}

As discussed supra, the Indiana Board of Law Examiners currently asks Indiana bar exam applicants the following questions, which have slightly changed since the court's decision in ACLU of Indiana:

25. Within the past five (5) years have you been diagnosed with or have you been treated for bipolar disorder, depression, or other emotional disorder, schizophrenia, paranoia, or any other psychotic disorder? 84

26A. Do you have any condition or impairment (including but not limited to, substance abuse, alcohol abuse, or a mental, emotional, or nervous disorder or condition) which in any way currently affects, or if untreated could affect,

\footnotetext{
${ }^{83}$ Id. at * 13 .

${ }^{84}$ Ind. Supreme Court Bd. of Law Exam'rs, supra note 16.
} 
your ability to practice law in a competent and professional manner? ${ }^{85}$

26B. Are the limitations or impairments caused by your mental health condition or substance abuse problem reduced or ameliorated because you receive ongoing treatment (with or without medication) or because you participate in a monitoring program? ${ }^{86}$

27. Have you ever raised the issue of consumption of drugs or alcohol or the issue of a mental, emotional, nervous, or behavioral disorder or condition as a defense, mitigation, or an explanation for your actions in the course of any administrative or judicial proceeding or investigation, any inquiry or other proceeding, or any proposed termination by an educational institution, employer, government agency, professional organization or licensing authority?87

Comparing these questions to those that were challenged in $A C L U$ of Indiana, it is clear that some adjustments have been made. Of course, former question 23, which asked whether an applicant had been diagnosed with or treated for any mental, emotional, or nervous disorders - which was ultimately struck down in $A C L U$ of Indiana - is no longer posed to applicants. 88 Additionally, current question 25 places temporal limitations on former question 22 by only requiring applicants to disclose whether they have been diagnosed with or treated for the enumerated disorders within the past five years. ${ }^{89}$ Question $26 \mathrm{~A}$ remains substantively identical to former question 24 . Further, Indiana has added question 27, which asks whether

${ }^{85} \mathrm{Id}$.

${ }^{86} I d$.

${ }^{87} I d$.

88 ACLU of Ind. v. Individual Members of the Ind. State Bd. Of Law Exam'rs, No. 1:09-CV-824-TWP-MJD, 2011 WL 4387470, at *13 (S.D. Ind. Sept. 20, 2011).

89 Ind. Supreme Court Bd. of Law Exam'rs, supra note 16. 
applicants have ever, among other things, used their mental, emotional, nervous, or behavioral disorders as an explanation or defense in one or more of several settings, such as judicial proceedings or investigations. ${ }^{90}$

As seen above, the Indiana Board of Law Examiners has amended its questions over and above the standard the court in $A C L U$ of Indiana determined would bring the questions into compliance with the ADA. However, as they stand, Indiana's questions still place additional criteria upon applicants based on their mental health histories. While placing additional criteria upon applicants alone is not a violation of the $\mathrm{ADA}$, it must be shown that such criteria are necessary to the Board of Law Examiners' licensing function and are not merely additional criteria placed on individuals based on "mere speculation, stereotypes, or generalizations." 91

\section{F. Department of Justice's Stance on Mental Health Inquiries}

In 2011, the Bazelon Center for Mental Health Law ${ }^{92}$ filed complaints against the Louisiana Bar Examiners. ${ }^{93}$ These complaints were made on behalf of two Louisiana attorneys who applied for admission to the Louisiana bar; however, because of their mental health histories, diagnoses, and treatments, these individuals were not granted full access to the Louisiana Bar but instead were admitted only on a

\footnotetext{
$90 \mathrm{Id}$.

9128 C.F.R. $\S 35.130$ (h) (2016).

92 The Judge David L. Bazelon Center for Mental Health Law is a national legal-advocacy organization representing people with mental disabilities. Who We Are, JUdGE DAVID L. BAZELON CENTER FOR MENTAL HEALTH, http://www.bazelon.org/Who-We-Are.aspx [https://perma.cc/ P5F2-WRTA] (last visited Apr. 20, 2016).

${ }^{93}$ Letter from Jocelyn Samuels, Acting Assistant Attorney General, to Bernette J. Johnson, Louisiana Supreme Court Chief Justice, Elizabeth S. Schell, Executive Director of Louisiana Supreme Court Committee on Bar Admissions, and Charles B. Plattsmier, Chief Disciplinary Counsel of the Louisiana Attorney Disciplinary Board (Feb. 5 , 2014) [hereinafter Letter from Jocelyn Samuels], available at http://www.bazelon.org/LinkClick.aspx?fileticket=7fvtHYXZawM\%3d\&t abid=698 [https:// perma.cc/DW6Z-YUYN].
} 
"conditional" basis. ${ }^{94}$ In response to the complaints filed on behalf of these individuals, the DOJ launched an investigation of Louisiana's attorney licensure system to determine whether it was compliant with Title II of the ADA. 95

At the time of this investigation, the Louisiana Bar Examiners required each prospective applicant to request that the NCBE prepare a character report. 96 To obtain an NCBE character report, a prospective applicant must, among other things, answer twenty-eight questions - four of which deal with an applicant's mental health. ${ }^{97}$ At the time, the NCBE posed the following questions to each applicant regarding his or her mental health histories:

25. Within the past five years, have you been diagnosed with or have you been treated for bipolar disorder, schizophrenia, paranoia, or any other psychotic disorder?

26A. Do you currently have any condition or impairment (including, but not limited to, substance abuse, alcohol abuse, or a mental, emotional, or nervous disorder or condition) which in any way currently affects, or if untreated could affect, your ability to practice law in a competent and professional manner? 26B. If your answer to Question 26(A) is yes, are the limitations caused by your mental health condition. . . reduced or ameliorated because you receive ongoing treatment (with or without medication) or because you participate in a monitoring program?

27. Within the past five years, have you ever raised the issue of consumption of drugs or alcohol or the issue of a mental, emotional, nervous, or behavioral disorder or condition as a defense, mitigation, or explanation for your actions in the course of any administrative or

\footnotetext{
94 Id. at 3.

$95 \mathrm{Id}$.

${ }_{96} I d$.

97 Id. at $4-5$.
} 
judicial proceeding or investigation; any inquiry or other proceeding; or any proposed termination by an educational institution, employer, government agency, professional organization, or licensing authority?98

When applicants responded affirmatively to questions 25 or 26 of the NCBE character report, they were required to complete a form authorizing each of their treatment providers to release information relating to their mental illness, including copies of medical records. ${ }^{99}$ Additionally, the applicants that responded affirmatively to these questions were required to provide detailed information about the condition and any treatment they had received for it. 100 Applicants that responded affirmatively to question 27 were required to thoroughly explain the situation through a supplement to the application; however, an affirmative response to question 27 did not result in additional forms requiring treating professionals' authorizations or a description of the condition. ${ }^{101}$

At the conclusion of its investigation into the Louisiana Bar Examiners' methods for inquiring into applicants' mental health histories, the DOJ concluded that the four questions asked by the Louisiana Bar Examiners via the NCBE questions were in violation of Title II of the ADA. 102 The DOJ deemed questions 25, 26A, 26B and 27 of the NCBE Request for Preparation of a Character Report to be a violation of the ADA because they did not serve the purported goal of screening out applicants that may not be mentally fit for the practice of law. ${ }^{103}$ Instead, the DOJ stated that these questions served as "eligibility criteria that screen out or tend to screen out individuals with disabilities based on stereotypes and assumptions about their disabilities and are not necessary to assess the applicants' fitness to practice

\footnotetext{
98 Id. at 5.

${ }^{99}$ Id. at 6.

$100 \mathrm{Id}$.

${ }^{101} I d$.

102 Id. at 18 .

${ }^{103} \mathrm{Id}$.
} 
law."104 It also found that the following additional "forms of discrimination flow from the use of [these questions]":

1) imposing additional burdens on applicants with disabilities who were required to provide additional reports and/or medical records; 2) making admissions recommendations on the existence of a mental health disability as opposed to conduct; 3) placing burdensome condition upon an applicants' legal licenses because of a mental health diagnosis and/or treatment; 4) imposing additional financial burdens on applicants and attorneys with disabilities, and 5) failing to protect the conditional medical information of applicants with disabilities. ${ }^{105}$

In recommending ways to move forward and bring its questions regarding applicants' mental health histories into compliance with Title II of the ADA, the DOJ, among other things, urged Louisiana to discontinue its use of "[q]uestions $25-27$ of the NCBE Request for Preparation of a Character Report as the questions were currently written."106 The DOJ also called for a modification of the Louisiana Supreme Court Rules to allow for the Louisiana Bar Examiners to screen applicants using conduct-based methods. ${ }^{107}$ The DOJ reasoned that a conduct-based method of inquiry, which would focus on specific behaviors that applicants had exhibited, would more successfully ensure that an individual's mental health diagnosis or treatment was not the basis for being referred for an additional evaluation during the application process. 108

\footnotetext{
${ }_{104} I d$.

$105 \mathrm{Id}$.

106 Id. at 31.

107 Id. at 22.

${ }_{108} I d$.
} 
The Louisiana Supreme Court and the DOJ entered into a settlement agreement in August 2014. ${ }^{109}$ The settlement agreement clearly stated that the Louisiana Supreme Court disagreed with the conclusions reached by the DOJ in its letter. ${ }^{110}$ The Louisiana Supreme Court also denied that any applicants for licensure or conditionally admitted attorneys were discriminated against. ${ }^{111}$ However, the statement affirmed that the Louisiana Supreme Court was willing to work with the DOJ to ensure that its questions were in complete compliance and to ensure a fair application process for applicants. ${ }^{112}$ Despite its explicit disagreement with the DOJ's stance on its questions, Louisiana agreed to cease using the standard NCBE questions $25-27$ as they were written at the time that the questions were challenged. ${ }^{113}$ Additionally, it was agreed that individuals involved in admissions to the Louisiana Bar will "[n]ot recommend or impose conditional admission solely on the basis of mental health diagnosis or treatment."114

However, it is important to note that the DOJ is an executive department of the United States Government.115 While it has power over all criminal prosecutions and civil suits in which the United States has an interest, 116 its opinion on Louisiana's bar exam questions does not bind state supreme courts or state agencies that choose character and fitness questions. Although the DOJ deemed the NCBE questions, as they were written at the time, a violation of Title II of the ADA, and an agreement was entered to cease use of those questions, states that continue to use them are not in violation of the law. For the questions to be deemed a violation of the $\mathrm{ADA}$ in a particular state, it will take an

109 Press Release, Settlement Agreement between the United States of America and the Louisiana Supreme Court Under the Americans With Disabilities Act (Aug. 15, 2014), available at http:// www.ada.gov/louisiana-supreme-court_sa.htm [perma.cc/UN6N-P4TB].

${ }^{110} \mathrm{Id}$.

111 Id.

112 Id.

${ }^{113} \mathrm{Id}$.

${ }^{114} I d$.

115 About DOJ, U. S. DEP'T. OF JUST.; available at https:// www.justice.gov/about [https://perma.cc/5LZK-YD8T] (last visited Apr. 20, 2016).

${ }^{116} \mathrm{Id}$. 
applicant to that state's bar who feels he or she has been discriminated against to bring action in court, and for the court to hold that the questions run afoul of the law.

Therefore, because states vary greatly in how they inquire into applicants' mental health histories, even if an applicant challenges a state's questions in a court of law, the decisions rendered by that jurisdiction regarding whether the questions are compliant with Title II of the ADA may differ between jurisdictions, even if the two states use essentially the same questions. Because of this, it is unlikely that there will be a uniform standard of questions on a state-by-state basis related to applicants' mental health histories until such case reaches the U.S. Supreme Court.

\section{G. The National Conference of Bar Examiners' Response}

The NCBE amended questions $25-27$ to the following:

25. Within the past five years, have you exhibited any conduct or behavior that could call into question your ability to practice law in a competent, ethical, and professional manner? 26A. Do you currently have any condition or impairment (including, but not limited to, substance abuse, alcohol abuse, or a mental, emotional, or nervous disorder or condition) that in any way affects your ability to practice law in a competent, ethical, and professional manner?

26B. If your answer to 26(A) is yes, are the limitations caused by your condition or impairment reduced or ameliorated because you receive ongoing treatment or because you participate in a monitoring or support program?

27. Within the past five years, have you asserted any condition or impairment as a defense, in mitigation, or as an explanation for your conduct in the course of any inquiry, any investigation, or any administrative or judicial proceeding by an educational institution, government agency, professional organization, or licensing authority, or in connection with an 
employment disciplinary or termination
procedure?117

If an applicant answers "yes" to either questions 26(A) or (B), the applicant must also complete a separate Form 7 and 8 for each service provider who has treated the applicant.118 Form 7 is an authorization to release medical information without limitation - in relation to mental illness and the use of drugs and alcohol to the NCBE. ${ }^{119}$ Form 8 requires a description of the condition or impairment, any treatment "program that includes monitoring or support," and contact information for attending physicians, counselors, and hospitals or institutions. ${ }^{120}$

The NCBE altered questions 25 and 26 to a conduct-based inquiry. Instead of asking whether the applicant has been diagnosed with or treated for bipolar disorder, schizophrenia, paranoia, or another psychotic disorder within the past five years, ${ }^{121}$ question 25 now asks whether any such diagnosis affects the applicant's ability to competently, ethically, and responsibly practice law. ${ }^{122}$ Additionally, the NCBE removed the "or if left untreated" language from question 26, which allows the question to now focus solely on the current impact that an applicant's mental, emotional, or nervous disorder or condition is having on his or her ability to practice law competently and professionally. ${ }^{123}$

It is clear, as question 27 remains unchanged, that the NCBE did not fully amend its questions to follow the DOJ's opinions. The DOJ considers question 27 to be unnecessary and in violation of the ADA. However, because the DOJ's opinions in the Louisiana matter are not binding authority, there was no duty for the NCBE to do so.

\footnotetext{
117 NAT'L CONF. OF BAR EXAM'RS, supra note 10.

118 Id. at 14 .

119 Id. at 28 .

$120 \mathrm{Id}$. at 29.

${ }^{121}$ Letter from Jocelyn Samuels, supra note 93.

122 NAT'L CONF. OF BAR EXAM'RS, supra note 10.

${ }^{123} \mathrm{Id}$.
} 


\section{ANALYSIS}

Although as a whole Indiana's bar exam application questions related to applicants' mental health histories are not as broad as they were prior to the ACLU of Indiana decision, they are still too broad to afford applicants the protections they are provided under Title II of the ADA. While the DOJ has made its stance clear and the NCBE has amended its own questions to be more conduct-focused, it is up to each state to decide whether or not to adopt these questions and how to interpret them.

Ultimately, it is the Indiana Supreme Court that is responsible for ensuring the state's licensing practices do not violate the $\mathrm{ADA}$. However, for a court of law to intervene and scrutinize a state's licensing practices, it first takes an individual with the belief that he or she has suffered discrimination by the state bar examiner on the basis of disability to bring suit. It is likely that this decision is not one that will be made lightly by such applicant, as it takes an extreme determination and in some instances, such as in the case of Kathleen Flaherty, a willingness to allow an in depth look into the applicant's mental health records, to challenge the way in which a state is screening its bar exam applicants.

A prudent state should constantly review its own questions and procedures to determine if it is best meeting its own needs and the needs of applicants rather than waiting for a discriminated individual to bring suit in a court of law. However, unfortunately, it does not seem that this is the approach that Indiana has taken. The NCBE amended its model questions to be more conduct-focused; however, as discussed supra, although these questions do not necessarily fully comply with the stance taken by the DOJ, it shows progress. Indiana, however, continues to use the former NCBE model questions - those which the DOJ has opined are a violation of the $\mathrm{ADA}$ - to screen its applicants.

\section{A. A Look at Indiana's Current Questions}

\section{Question 25}

Indiana's current question 25 - which is similar in wording to the former question 22 - now requires individuals 
who have been diagnosed with or have been treated for what the court in ACLU of Indiana deemed a "serious condition" to only disclose that information if such diagnosis or treatment has occurred within the past five years. The court in $A C L U$ of Indiana allowed former question 22 to stand as it was written, despite the fact that it had no temporal limit because the types of conditions being asked about were those that were likely to recur throughout an applicant's lifetime. ${ }^{124}$ Placing a temporal limit on the question makes it seem that the Indiana Board of Law Examiners has taken it upon itself to further limit its inquiries into applicants' mental health histories; however, this is not necessarily so.

Although there is now a five-year limit within which an applicant must disclose whether he or she has been diagnosed or treated for a "serious condition," current question 25 now includes language requiring an applicant to disclose any "other emotional disorder" or "any other psychotic disorder." 125 No definition is provided for what constitutes an emotional disorder or a psychotic disorder, so these categories have the potential to serve as a catchall, encompassing almost an endless number of conditions that an applicant would be required to disclose on his or her character and fitness application.

The "emotional" or "psychotic" disorder language of question 25 is also similar to the language of a question posed by the Virginia bar that was ultimately held to be a violation of Title II of the ADA. ${ }^{126}$ In Clark v. Virginia Board of Bar Examiners, an applicant seeking admission to the Virginia bar challenged the application questions asked regarding her mental health as being in violation of the ADA. ${ }^{127}$ The applicant, Julie Ann Clark, was a graduate of George Mason University Law School and "suffers from a condition that was previously diagnosed as 'major depression, recurrent." 128

${ }_{124}$ ACLU of Ind. v. Individual Members of the Ind. State Bd. Of Law Exam'rs, No. 1:09-CV-824-TWP-MJD, 2011 WL 4387470, at *2 (S.D. Ind. Sept. 20, 2011).

${ }^{125}$ Ind. Supreme Court Bd. Of Law Exam'rs, supra note 16.

126 See Clark v. Va. Bd. Of Bar Exam'rs, 880 F. Supp 430, 437-438

(E.D. Va. 1995).

${ }^{127}$ Id. at 433.

128 Id. at 432. 
On her bar application, Ms. Clark was asked to answer a question that stated, "[h]ave you within the past five (5) years, been treated or counseled for a mental, emotional, or nervous disorders?" 129 She declined to answer this question, which if responded to in the affirmative would have required her to provide the "dates of treatment or counseling," contact information for her health care provider, hospital, or institution, and a complete description of the diagnosis and treatment. ${ }^{130}$ Although "pursuant to agreement of counsel," the Virginia Board of Bar Examiners allowed Ms. Clark to sit for the Virginia bar exam without answering the question and providing the requisite information, it would not grant her a license until she did so. 131

Ultimately, the court found that the question subjected applicants to discrimination based on their disability, as additional eligibility criteria was imposed on individuals with disabilities. 132 Thus, in order for the question at issue to comply with Title II of the ADA, it would have to be necessary to the performance of the Virginia Board of Bar Examiners' licensing function. However, the court did not find that the question was necessary. ${ }^{133}$ Instead, it found that the question was not a strong indicator of identifying unfit applicants and that it had a strong deterrent effect on applicants. ${ }^{134}$

This same logic and reasoning can be applied to Indiana's question 25. The question places additional eligibility criteria on Indiana bar exam applicants without being necessary to the Indiana Board of Law Examiners' licensing function - the power it has to grant licenses to individuals to practice law within the state. The extremely broad scope of the listed conditions in which an individual is required to disclose a diagnosis or treatment is likely to have a deterrent effect on applicants from either seeking treatment or from being forthcoming on the application, which is completely adverse to the aim that the question is intended to serve.

\footnotetext{
${ }^{129} I d$. at 433.

$130 \mathrm{Id}$.

${ }_{131} I d$

132 Id. at 442 .

133 Id. at 446.

134 Id. at 446.
} 
These concerns are of the utmost importance, as "[a]pproximately 1 in 4 people have a mental health problem." 135 However, in the United States and Europe, up to $75 \%$ of these people will not receive treatment, in part because of the stigma associated with receiving treatment for mental health related issues, which perpetuates individuals' fear of having to disclose a mental health condition. 136

Although the scope of Indiana's question 25 is limited to five years, there remains no focus on an applicant's behavior or specific conduct that he or she has exhibited within the past five years. Instead, the question solely focuses on an applicant's diagnosis and/or treatment. This type of inquiry is likely to result in false positives, as "there is simply no empirical evidence that applicants' mental health histories are significantly predictive of future misconduct or malpractice as an attorney." 137

Apart from question 25 being in violation of Title II of the ADA because of the additional eligibility criteria that it places on applicants that respond affirmatively, and because it is not necessary to the Indiana Board of Law Examiners' licensing function, it also raises valid public policy concerns. One of the main issues surrounding the states' inquiries into applicants' mental health histories is whether or not such inquiries will deter individuals who wish to seek treatment or speak with a counselor because individuals fear receiving a diagnosis they must disclose on the character and fitness application.

Additional concerns arise when applicants decide to get treatment, but are not fully forthcoming about their symptoms with their physicians out of fear that they will be required to disclose any diagnosis they receive. ${ }^{138}$ Because

135 Stigma 'Key Deterrent' in Accessing Mental Health Care, KInGS C. LONDON NEWS (Feb. 26, 2014), http://www.kcl.ac.uk/ioppn/news/ records/2014/February/Stigma-key-deterrent-in-accessing-mentalhealth-care.aspx/[https://perma.cc/2LXK-W8MX].

${ }^{136} \mathrm{Id}$.

${ }^{137}$ Bauer, supra note 13 , at 141.

138 See, e.g., Clark v. Va. Bd. Of Bar Exam'rs, 880 F. Supp 430, 44546 (E.D. Va. 1995);

Hughes, supra note 23, at 189-190. See also Chris Iliades, Are You Telling Your Doctor the Truth About Your Depression?, EvERYDAY HEALTH (Jan. 
any successful patient-physician relationship rests on full disclosure from the patient, any treating physician with less than complete understanding of a patient's condition will not be able to provide the best care for the patient.139 Patients' ability to feel comfortable with their physician often is synonymous with them being candid with their treating physicians. This candidness is especially imperative in instances of mental illness. Providing an abridged version of symptoms and feelings may result in a misdiagnosis, which may result in the prescription of medication when medication is not needed, a wrong dosage of a medication, or a prescription for the wrong type of medication. One or a combination of these events could worsen an individual's symptoms or not help at all, which could further inhibit his or her desire to seek help.

\section{Question 26}

Question 26A, which asks whether an applicant has a condition or impairment that in any way currently affects, or if untreated could affect, his or her ability to practice law is seemingly identical to former question 24 , which the court in $A C L U$ of Indiana allowed to stand because of its focus on the current time period and of an individual's current ability to practice law. ${ }^{140}$ However, it does not appear that the entire question is truly focused on an individual's current ability to practice law and therefore, it may be considered to run afoul of Title II of the ADA.

The first portion of the question is focused on whether an applicant has a condition or impairment that is currently affecting him or her in a way that would impede upon the applicant's ability to practice law. Because this focuses on an applicant's current behavior as a result of his or her mental fitness, it is likely suitable under the ADA. By inquiring into the conduct of the applicant, this question is not stereotyping based upon the applicant's disability, which is what Title II

23, 2013), http://www.everydayhealth.com/health-report/ majordepression/telling-psychiatrist-the-truth.aspx [perma.cc/X4DY-8WHK].

139 Clark, 880 F. Supp. at 438-440.

${ }_{140}$ ACLU of Ind. v. Individual Members of the Ind. State Bd. Of Law Exam'rs, No. 1:09-CV-824-TWP-MJD, 2011 WL 4387470, at *13 (S.D. Ind. Sept. 20, 2011). 
of the ADA seeks to prohibit. Although - to an extent question 26A does impose additional eligibility criteria on an applicant based upon his or her disability, for it to be considered a violation of Title II of the ADA, it would have to be shown that the question was unnecessary to the Indiana Board of Law Examiners' licensing function.

This question has a more direct relation to the Board's goals of inquiring into an applicant's mental health history to screen out applicants that may pose a risk to themselves or others in the course of the practice of law. It requires applicants to disclose a condition only if it is currently affecting them in a way that may conflict with their ability to practice law in a competent manner, not solely because an applicant has been diagnosed with a certain disorder or is receiving treatment for a disorder. Thus, the burden it places on applicants is not an undue burden, but it is rather seeking to inquire into specific conduct and behaviors that may pose an actual risk to the applicant's ability to effectively engage in the practice of law.

Although there are certainly valid arguments as to why the first part of question 26A is necessary to the Indiana Board of Law Examiners' licensing function, the question as a whole is overly broad, which may have negative implications. Because of the question's broad nature, it may deter applicants from applying to the bar, or deter those who do apply from responding truthfully to the question. Additionally, applicants may not consider the type of behavior they are exhibiting to be the type of condition or impairment that needs to be disclosed. In sum, the first portion of question 26A makes a more conduct-focused inquiry, which is the type of question that the DOJ opines is compliant with Title II of the ADA. As such, it is much more suitable to providing applicants' the rights they are afforded under the ADA. However, because of the broad nature of the question, it is possible that this question will not truly assist the Indiana Board of Law Examiners in screening out the applicants that may pose a threat.

Apart from the public policy concerns that the question may deter applicants from applying to the bar, or if they do apply, from providing full disclosure, question $26 \mathrm{~A}$ seems to be a well-suited question both to protect the rights and privacy of applicants afforded to them under Title II of the 
ADA. However, the 'if untreated could affect' language bears no connection to an applicant's current mental fitness. Rather, it is solely hypothetical in nature. By including this portion of the question, far more applicants will be required to respond affirmatively and will be required to complete a Form B-1. Form B-1 requires the applicant to list dates of treatment, the name and contact information of his or her provider(s), and a detailed description of the "type of problem, condition, impairment, diagnosis, treatment, and/or monitoring program."141

Additionally, if an applicant responds in the affirmative to question 26A, he or she must answer 26B, which asks whether the limitations or impairments resulting from the applicant's mental health condition are reduced or improved because of treatment. If an applicant is undergoing treatment that improves the condition, and thus answers question $26 \mathrm{~B}$ affirmatively, the applicant is required to fill out another Form B-1 detailing information about that treatment and the contact information for his or her provider.

Overall, the second prong of question $26 \mathrm{~A}$ weakens the arguments that asking applicants this question is necessary to the Indiana Board of Law Examiners' licensing function. As a whole, question 26A places additional eligibility criteria upon applicants regarding their mental health status and requires them to opine on the types of behavior that they would exhibit if their conditions were left untreated. This forces applicants who are, and have always been, treated for their condition to determine whether they would behave in a way that was not competent or ethical in the practice of law if they were not being treated.

Further, the "if left untreated" language of question 26A requires a greater number of individuals to respond affirmatively to this question. As it is asked, individuals who have a condition or impairment that is under control and would not affect their ability to practice law in a competent manner would not be required to respond affirmatively.

\footnotetext{
${ }^{141}$ Ind. Supreme Court Bd. Of Law Exam'rs, Character \& Fitness Questionnaire Form B-1, APPLICATION INFORMATION (2016), a vailable at https://myble.courts.in.gov/browseapplication.action?id=9 (last visited Apr. 20, 2016) (select "Browse Form" beside "Character and Fitness Questionnaire," click "General Questions" in the dropdown bar, select "yes" under question 26A).
} 
However, the second prong of the question may require such individuals to have to disclose their condition anyway if the untreated condition would affect their behavior. Like the "other emotional" or "psychotic" disorder language in question 25, inquiring into the hypothetical behavior of an applicant is too broad of a reach, and does not effectively protect the rights and privacy of applicants.

\section{Question 27}

Indiana's question 27 , which seeks information regarding whether a mental health condition has been used as a defense, mitigating factor, or explanation for an applicant's actions, once again fails to focus on the current conduct or behavior of an applicant. This question is extremely similar to the NCBE's question 27 both prior to and after the changes it made to questions 25 and 26.

The Indiana bar exam application thoroughly investigates applicants' experiences with civil and criminal litigation, employment history and educational history by asking specific, direct questions. Therefore, there is ample opportunity to question applicants on such events, including any such defenses, which if answered affirmatively, will allow for the applicant to be further questioned or for additional information to be obtained. Thus, it may be argued, as it was by the DOJ, that such question is unnecessary. ${ }^{142}$

Because many of the types of behavior and conduct that this question asks about are thoroughly covered by other sections of the Indiana bar exam, there is a chance that this may be considered placing additional criteria upon applicants based upon their disability. However, if whether a question focuses on an applicants' current conduct and/or behavior is used as the sole yardstick to determine compliance with Title II of the ADA, question 27, to the extent it reveals such current conduct or behavior, may be considered compliant.

${ }^{142}$ Letter from Jocelyn Samuels, supra note 93, at 23. 


\section{B. Summary}

The similarities between Indiana's current questions relating to mental health and the former NCBE questions, which the DOJ opined are in violation of Title II of the ADA, should not be ignored. For these mental health related inquiries to comply with Title II of the ADA, it must be shown that despite the additional eligibility criteria that the questions place on applicants based on their mental health status, the questions are necessary to the Indiana Board of Law Examiners' licensing function. However, as it has been demonstrated, it is unlikely that Indiana's questions, as currently written, are truly necessary. Thus, the questions should be re-evaluated to ensure that applicants are being afforded the full protections provided to them under Title II of the ADA.

While the simple solution may be to amend all mental health-related questions to conduct-based questions in order to comply with what the DOJ deems ADA appropriate questions, it may not truly remedy all of the issues associated with inquiring into applicants' mental health histories. Thus, although bringing Indiana's questions into full compliance with Title II of the ADA is surely a positive step to rectifying the issues posed by inquiring into applicants' mental health histories, the only way to truly remedy the deterrent effect caused by such inquiry is to begin to work toward removing the stigma surrounding mental illness.

\section{CONCLUSION}

The high rates of depression and mental illness among both law students and practicing attorneys in the United States make states' interest in ensuring applicants' mental fitness one of high importance. By having a screening process in place to determine whether bar exam applicants are mentally fit to practice law, states are ensuring safety not only for the attorneys themselves, but also for the attorneys' colleagues and clients.

Indiana made adjustments to the ways in which it questions applicants regarding their mental health histories following the $A C L U$ of Indiana decision. However, the measures taken were not enough to bring Indiana's mental 
health related questions in compliance with Title II of the $\mathrm{ADA}$. Indiana's current approach delves too deeply into the generalities of an applicant's mental health history instead of inquiring into how any such conditions have impacted the behavior and conduct of the applicant. This places additional eligibility criteria on these applicants based upon the stereotypes and generalizations associated with their mental health condition that are not necessary to the Board of Law Examiners' licensing function - a violation of Title II of the ADA.

Amending bar exam questions to be more behavior and conduct focused will bring Indiana's mental health related questions into compliance with Title II of the ADA. Inquiring into specific behaviors that may interfere with an applicant's ability to practice law would still place additional criteria upon those applicants with mental conditions who, based upon their responses to the questions, would be required to disclose additional information. However, these additional criteria are placed upon the applicants because they have exhibited behaviors that may impact their effectiveness to practice law, not solely because they have been diagnosed with or are receiving treatment for a mental health condition. Additionally, amending Indiana's mental health related questions to conduct-specific inquiries would likely lessen the number of false positives during an application cycle. This would reduce the extra attention required of the Indiana Board of Law Examiners during an application cycle, as it would no longer be expending time and resources to further inquire into perfectly fit applicants' character and fitness eligibility.

While designing questions that comply with Title II of the ADA is important to protect applicants' privacies and rights afforded to them by the law, there are far greater issues underlying how Indiana questions its applicants' mental health histories. Ultimately, the stigma surrounding mental health related issues is the main cause for concern. Until this stigma is removed, zealous advocates that are passionate about the law will be deterred from pursuing careers in law solely because of the fear of having to disclose their mental health status. Current law school students who are experiencing concerning symptoms will be hesitant to get help for fear of being flagged during the bar application 
process, of conditional admission, or of being referred to JLAP. Students that have been diagnosed with and are being treated for mental health related issues may be hesitant to be fully candid with their treating physicians or to be truthful in their disclosures on the bar exam application, which only hinders those individuals themselves from getting the best care.

In both the law school and legal profession cultures, more discussion needs to be had regarding mental illness. The topic needs to be de-stigmatized and cease being considered taboo. It needs to be more than a pamphlet handed out at $1 \mathrm{~L}$ orientation or a topic subtly mentioned at firm in-service meetings. Until the stigma surrounding mental illness is removed, any set of questions inquiring into bar exam applicants' mental health histories will not fully suffice, regardless of whether they are compliant with Title II of the ADA. Only by changing the way in which the legal profession views and discusses mental illness will it become possible to create the illusive set of questions that "[strikes] the perfect balance between detecting problematic bar applicants and respecting applicants' privacy" that the court in $A C L U$ of Indiana alluded to. ${ }^{143}$ 